\title{
RESEARCH
}

Open Access

\section{Human foreskin-derived dermal stem/ progenitor cell-conditioned medium combined with hyaluronic acid promotes extracellular matrix regeneration in diabetic wounds}

\author{
Yu Xin ${ }^{1 \dagger}$, Peng $\mathrm{Xu}^{1,2+}$, Xiangsheng Wang ${ }^{1,2}$, Yunsheng Chen ${ }^{1}$, Zheng Zhang ${ }^{1 *}$ and Yixin Zhang ${ }^{1 *}$
}

\begin{abstract}
Background: Diabetic wounds remain a challenging clinical problem, which requires further treatment development. Published data showed that dermis-derived stem/progenitor cells (DSPCs) display superior wound healing in vitro. The beneficial effects of DSPCs are mediated through paracrine secretion, which can be obtained from conditioned medium (CM). Hyaluronic acid (HA) is especially suitable for skin regeneration and delivering bioactive molecules in CM. This study investigated the effect of human foreskin-derived dermal stem/progenitor cell (hFDSPC)-CM combined with HA on a diabetic mouse model and relevant mechanism in vitro.

Methods: hFDSPCs and human adipose-derived stem cells (hADSCs) were identified, and the respective CM was prepared. PBS, HA, hFDSPC-CM combined with HA, or hADSC-CM combined with HA was topically applied to mice. $\mathrm{HE}, \mathrm{CD} 31, \mathrm{CD} 68, \mathrm{CD} 86$, and CD206 staining was performed to evaluate gross wound condition, angiogenesis, and inflammation, respectively. Masson and Picrosirius red staining was performed to evaluate collagen deposition and maturation. The effects of hFDSPC-CM and hADSC-CM on human keratinocyte cells ( $\mathrm{HaCaT}$ ) and fibroblasts were evaluated in vitro using CCK-8 and EdU assays to determine cell viability and proliferation, respectively. The scratch assay was performed to evaluate cell migration. Tube formation assay was performed on human umbilical vein endothelial cells (HUVECS) to confirm angiogenesis. Extracellular matrix (ECM) metabolic balance-related genes and proteins, such as collagen I (COL 1), collagen III (COL 3), fibronectin (FN), a-SMA, matrix metalloproteinases 1 (MMP1), matrix metalloproteinases 3 (MMP-3), and transforming growth factor-beta 1 (TGF- $\beta 1$ ), were analysed.

(Continued on next page)
\end{abstract}

\footnotetext{
*Correspondence: zhangzheng958@163.com; zhangyixin6688@163.com

${ }^{+}$Yu Xin and Peng Xu contributed equally to this work.

'Department of Plastic and Reconstructive Surgery, Shanghai 9th People's

Hospital, Shanghai Jiao Tong University School of Medicine, 639 Zhi Zao Ju Road, Shanghai 200011, China

Full list of author information is available at the end of the article
}

C C The Author(s). 2021 Open Access This article is licensed under a Creative Commons Attribution 4.0 International License, which permits use, sharing, adaptation, distribution and reproduction in any medium or format, as long as you give appropriate credit to the original author(s) and the source, provide a link to the Creative Commons licence, and indicate if changes were made. The images or other third party material in this article are included in the article's Creative Commons licence, unless indicated otherwise in a credit line to the material. If material is not included in the article's Creative Commons licence and your intended use is not permitted by statutory regulation or exceeds the permitted use, you will need to obtain permission directly from the copyright holder. To view a copy of this licence, visit http://creativecommons.org/licenses/by/4.0/ The Creative Commons Public Domain Dedication waiver (http://creativecommons.org/publicdomain/zero/1.0/) applies to the data made available in this article, unless otherwise stated in a credit line to the data. 
(Continued from previous page)

Results: hFDSPC-CM combined with HA showed superior wound closure rate over hADSC-CM. Histologically, the hFDSPC-CM combined with HA group showed significantly improved re-epithelialisation, angiogenesis, antiinflammation, collagen regeneration, and maturation compared to hADSC-CM combined with HA group. In vitro assays revealed that hFDSPC-CM displayed significant advantages on cell proliferation, migration, and ECM regeneration through a TGF- $\beta / S m a d$ signalling pathway compared with hADSC-CM.

Conclusions: hFDSPC-CM combined with HA was superior for treating diabetic wounds. The underlying mechanism may promote proliferation and migration of epidermal cells with fibroblasts, thus leading to ECM deposition and remodelling. Reduced inflammation may be due to the above-mentioned mechanism.

Keywords: Human foreskin, Dermal stem/progenitor cells, Conditioned medium, Diabetic wound healing, Extracellular matrix

\section{Background}

Diabetic wounds remain a challenging clinical problem and are characterised by deficient chemokine production and angiogenesis, decreased fibroblast migration and proliferation, and an abnormal inflammatory response $[1,2]$. Current treatment for diabetic wounds include customised dressings, surgical debridement, negative pressure wound therapy, antibiotics, and hyperbaric oxygen [3-5], without targeting the underlying pathophysiology, leading to treatment failure [4].

Although recent studies showed that mesenchymal stem cells (MSCs) isolated from the adipose tissue, bone marrow, umbilical cord blood, and skin exhibited similarity and have been proven to accelerate diabetic wound healing, they have specific features from distinct niches [6-11]. Zomer et al. revealed a greater in vitro wound closure capacity of dermis-derived MSCs than adiposederived MSCs, showing that dermis-derived MSCs are unique for skin wound healing [12]. Particularly, as a discarded waste, the human foreskin exhibited attractive potential as an abundant source of MSCs for clinical application without ethical concerns [13].

Notably, the beneficial effects of MSCs are mediated through paracrine secretory mechanisms, which are called "secretomes" and mainly consist of various growth factors, microRNA, proteasomes, and extracellular vesicles (EVs). These are more suitable for clinical applications than cell therapy because they circumvent many safety concerns associated with cell therapy. Extracellular vesicles showed good outcomes for diabetic wounds, but the tedious processes of EV preparation limit their application. In contrast, conditioned medium (CM) from MSCs exhibits many merits over EVs, such as being cheaper and quickly obtained, and may yield either equipotent or more potent preparation for clinical application [14]. In addition, skin wound dressings also play crucial roles in improving wound healing. Among which, hyaluronic acid (HA), as a kind of off the shelf biocompatible polymer, is especially suitable for skin regeneration, due to its natural existence in skin tissue and the ability to locally deliver entrapped bioactive molecules [15]. In addition, therapies that integrated HA with other components such as exosomes and silver particles exhibited enhanced healing effects [16, 17]. And HA-based wound fillers can be enriched with further bioactive components, such as conditioned media.

To date, some foreskin-derived fibroblast products have been commercially available due to their prohealing effect for wound healing, such as Dermagraft ${ }^{\circ}$ (Organogenesis, Inc.) and Apligraf (Organogenesis, Inc.). However, the effects of administering human foreskin-derived dermal stem/progenitor cell (hFDSPC)conditioned medium (hFDSPC-CM) combined with HA on a diabetic mouse model remain uncertain. To this end, hFDSPC-CM with HA was prepared and topically applied to diabetic mice. Human adipose-derived stem cell-conditioned medium (hADSC-CM) was selected as the positive control, which is proven to have obvious therapeutic effect on this disease [18]. In vitro assays were further performed to illuminate the corresponding mechanism of hFDSPC-CM in promoting skin wound healing.

\section{Methods \\ Cell isolation and culture}

All tissue samples were collected from Shanghai Ninth People's Hospital, with written consent obtained from the patients for experimentation prior to surgery. The study was approved by the Ethics Committee of Shanghai Jiao Tong University School of Medicine.

For hADSC isolation, human adipose tissues, obtained from 9 healthy female donors (age range 23-38 years) who underwent liposuction (informed consent was obtained from donors for using adipose tissues in experiment), were mixed as a cell pool, rinsed with saline, and separated from blood vessels and excess fat. Then, samples were digested with collagenase type I (SigmaAldrich, St. Louis, MO, USA) for $1-2 \mathrm{~h}$ at $37^{\circ} \mathrm{C}$. The samples were then filtered through a $70-\mu \mathrm{m}$ cell strainer (BD Biosciences, Mississauga, Canada) and mixed with 
low-glucose Dulbecco's modified Eagle's medium (DMEM, Gibco, NY, USA) supplemented with $10 \%$ foetal bovine serum (FBS, Gibco, NY, USA) and 1\% antibiotics (penicillin $100 \mathrm{U} / \mathrm{ml}$, streptomycin $100 \mathrm{U} / \mathrm{ml}$, Gibco), and then centrifuged at $300 \times g$ for $10 \mathrm{~min}$. The supernatant and oil drop were discarded. The precipitated cells were resuspended in DMEM, supplemented with $10 \%$ FBS and $1 \%$ antibiotics, and then cultured in a humidified incubator at $37^{\circ} \mathrm{C}$ with 5\% CO2. The culture medium was changed every 2 days. Passage 0 to 3 cells were used in the following experiments.

For hFDSPC isolation, human foreskin tissue was obtained from 9 children (age range 2-7 years) undergoing circumcision (informed consent was obtained from the parents of the children for using foreskin tissue in experiment) and mixed as a cell pool. To separate dermis from epidermis, the donated tissues were harvested, minced, and immersed in Dispase II (Roche Applied Science, Indianapolis, IN, USA) overnight at $4{ }^{\circ} \mathrm{C}$. The remaining dermis was separately minced into small pieces followed by digestion with $0.2 \%$ collagenase type IV (Sigma-Aldrich) for 2-3 h. The digested cells were resuspended in minimum Eagle's medium (Gibco, Ontario, Canada) supplemented with $10 \%$ FBS and $1 \%$ antibiotics. Cells were seeded on tissue culture plates at $1 \times 10^{3}$ cells $/ \mathrm{cm}^{2}$ and cultured for $24 \mathrm{~h}$, and then washed with phosphate-buffered saline (PBS, Gibco, NY, USA) to remove residual non-adherent cells. After 5 days, the adherent cells were selected for superior colonies in form and quantity for collection and passage. Cells at passages 0 to 3 were used in the following experiments.

For in vitro mechanistic studies, excess skin tissues obtained from 5 female donors (age range 26-36 years; informed consent was obtained from the donors) undergoing plastic surgery were mixed as a cell pool for human fibroblast isolation. The tissues were processed within $2 \mathrm{~h}$ post-surgical excision. Cell isolation and culture methods were in accordance with a previous study [19]. The third passage cells were used in the following experiments.

Human immortal keratinocyte cells $(\mathrm{HaCaT})$ and human vascular endothelial cells (HUVECs) were purchased from the American Type Culture Collection (ATCC, Rockville, MD, USA) and maintained in DMEM supplemented with $10 \% \mathrm{FBS}$ and $1 \%$ antibiotics at $37^{\circ} \mathrm{C}$ with $5 \% \mathrm{CO}_{2}$. The culture medium was changed every 2 days.

\section{Preparation of $\mathrm{CM}$}

Third passage hADSCs and hFDSPCs were washed with PBS thrice and starved in DMEM for $48 \mathrm{~h}$. Cell supernatants $(500 \mathrm{~mL})$ were collected, centrifuged at $300 \times g$ for $10 \mathrm{~min}$, and filtered through a $0.22-\mu \mathrm{m}$ filter to remove cell debris. The conditioned medium was then concentrated with a cut-off value of $10 \mathrm{kDa}$ (Amicon Ultra-15,
Millipore, MA, USA) and centrifuged at $3000 \times g$ for $1 \mathrm{~h}$, eventually condensed into $25 \mathrm{~mL}$. The concentrated CM was frozen and stored at $-80^{\circ} \mathrm{C}$ until use. Before application, CM was quantified using a BCA Protein Assay Kit (Beyotime, Shanghai, China, Cat: P0012S) according to the instruction of the kit.

\section{Colony forming unit (CFU) assay}

Passages 1-3 of hFDSPCs were cultured and plated in 6well plates at a density of 50 cells $/ \mathrm{cm}^{2}$. After 7 days, individual clones were identified under an inverted microscope (Leica, Wetzlar, Germany), fixed with $4 \%$ paraformaldehyde, and stained with $2 \%$ crystal violet for $15 \mathrm{~min}$. Colonies containing 10 or more cells were selected, and the number of cells per colony was quantified. The experiment was repeated three times.

Flow cytometry analysis of cell surface marker expression The hFDSPCs or hADSCs (passage 3) cell suspension was prepared at a density of $10^{6}$ cells per $100 \mu \mathrm{L}$. Thereafter, antibodies $(10 \mu \mathrm{L})$ were added to each $100 \mu \mathrm{L}$ cell suspension, followed by incubation at room temperature for $30 \mathrm{~min}$ and analysis using flow cytometry (FACSCalibur, BD Biosciences, Mississauga, Canada).

All antibodies were purchased from BioLegend (San Diego, CA, USA) including the following: FITCconjugated antibodies for CD90 (Cat: 328107), CD44 (Cat: 338803), CD105 (Cat: 323203), CD34 (Cat: 343603), CD45 (Cat: 368507), CD19 (Cat: 392507) or PE-conjugated antibodies CD29 (Cat: 303003), CD13 (Cat: 301703), CD59 (Cat: 304707), CD31 (Cat: 303105), CD133 (Cat: 372803), CD11b (Cat: 301305), HLA-DR (Cat: 307605), and CD73 (Cat: 344003). Isotype control IgG (Cat: 400107; 400111) was used to stain the cells as controls. The experiment was repeated three times.

\section{Induction of osteogenic, chondrogenic, and adipogenic differentiation}

A trilineage-induced differentiation experiment including osteogenesis, adipogenesis, and chondrogenesis of hFDSPCs or hADSCs was performed to identify multiple differentiation potential. Briefly, hFDSPCs (passage 2) were cultured in 6-well plates at a density of $5 \times 10^{4} /$ $\mathrm{cm}^{2}$ with human MSC osteogenic and adipogenic differentiation medium (Cyagen Biosciences Inc., Sunnyvale, USA) for adipogenesis or osteogenesis induction, respectively. After a 2-week culture, alizarin red and oil red $\mathrm{O}$ staining was employed to evaluate osteogenesis and adipogenesis, respectively. For chondrogenesis, $3 \times$ $10^{5}$ cells were resuspended in a $15-\mathrm{mL}$ polypropylene centrifuge tube and centrifuged at $250 \times g$ for $4 \mathrm{~min}$, and then resuspended in $0.5 \mathrm{~mL}$ human MSC chondrogenic differentiation medium (Cyagen Biosciences Inc., 
Sunnyvale, USA) and centrifuged at $150 \times g$ for $5 \mathrm{~min}$. The pellet was cultured for 3 weeks, and then fixed in $4 \%$ paraformaldehyde and stained with Alcian blue.

\begin{abstract}
Animals
All experiments were approved and performed under the guidelines of the Ethics Committee of Shanghai Jiao Tong University School of Medicine. Male C57BLKS/J $\mathrm{db} / \mathrm{db}$ diabetic mice (age, 8 weeks; weight, 36.5-40.2 g) were purchased from GemPharmatech Co., Ltd. (Jiangsu, China). Mice were fed and maintained under a 12-h light/dark cycle at an ambient temperature of $23-25{ }^{\circ} \mathrm{C}$ with $55-65 \%$ humidity. Mice were given standard rodent chow and water ad libitum.
\end{abstract}

\section{Diabetic mouse wound healing model}

The mice were randomly divided into four groups $(n=$ 5): (1) control group, treated with $100 \mu \mathrm{L} \mathrm{PBS;} \mathrm{(2)} \mathrm{HA}$ group, treated with $100 \mu \mathrm{L} \mathrm{1.5 \%} \mathrm{HA} \mathrm{(Sodium} \mathrm{hyaluron-}$ ate, Sigma-Aldrich, Missouri, USA, Cat: 63357, isolated from Streptococcus equi with a molecular weight of 1 , 500,000-1,750,000); (3) hADSC-CM + HA group, treated with $100 \mu \mathrm{g} / \mathrm{mL}$ condensed hADSC-CM in $1.5 \%$ HA $(100 \mu \mathrm{L}$ in total); and (4) hFDSPC-CM + HA group, treated with $100 \mu \mathrm{g} / \mathrm{mL}$ hFDSPC-CM in $1.5 \%$ HA $(100 \mu \mathrm{L}$ in total). All the mice were anaesthetised with isoflurane inhalation. After being shaved and depilated, a 6-mm-diameter circle, single, dorsal, full-thickness wound (including panniculus carnosus) was produced. The treatment was administered to all mice 1 day after the wound model was established as follows: sodium hyaluronate powder was dissolved in deionised water to form a $1.5 \%$ hydrogel $(\mathrm{w} / \mathrm{v})$. Condensed hFDSPC-CM/ hADSC-CM $(10 \mu \mathrm{g})$ was mixed with $100 \mu \mathrm{L} 1.5 \%$ hydrogel and shaken by vortexing to form hADSC-CM + HA/ hFDSPC-CM + HA mixture for application. A total of $100 \mu \mathrm{L}$ HA hydrogel or the above mixture was applied to the wound area. The hydrogel was very sticky, so no extra measure was taken to fix it, and this sticky feature enabled the CM to remain on the wound area.

\section{Gross evaluation of wound closure}

Digital photographs of the wound were captured on days $0,3,7,10$, and 14 . Time to wound closure was defined as the time at which the wound bed was completely reepithelised. The wound areas were analysed by tracing the wound margins and calculated using Image-Pro Plus software version 6.0 (Media Cybernetics, Rockville, USA). The closure rate was expressed as a percentage area of the original wound area.

\section{Histological staining}

On day 14, mice were sacrificed and full-thickness, cross-sectional tissue samples were obtained (specimens traversed the entire diameter of the wound and included unwounded skin on both sides). Specimens were then fixed in $4 \%$ paraformaldehyde, paraffin-embedded, and sectioned at $8 \mu \mathrm{m}$. Haematoxylin and eosin (HE) and Masson's trichrome staining was performed for histological analyses.

For immunohistochemistry, samples from three animals $(n=3)$ in each group were sectioned and analysed for quantification of CD31, CD68, CD86, and CD206. Specimen sections were incubated with anti-CD31 (Abcam, Cambridge, UK, Cat: ab76533, 1:1000), antiCD68 (Abcam, Cambridge, UK, Cat: ab213363, 1:2000), anti-CD86 (Abcam, Cambridge, UK, Cat: ab119857,1: 200), and anti-CD206 (Abcam, Cambridge, UK, Cat: 60143-1-lg, 1:1000) at $37^{\circ} \mathrm{C}$ for $2 \mathrm{~h}$, followed by incubation with horseradish peroxidase- (Jackson ImmunoResearch, Madison, USA, Cat: 111-035-003, 1:1000) or PEconjugated secondary antibody (Jackson ImmunoResearch, Madison, USA, Cat:111585003, 1:1000). Haematoxylin or DAPI (1:1000, Boster, Wuhan, China, Cat: AR1176) was used to stain cell nucleus. The sections were examined under light microscopy (Leica, Wetzlar, Germany). Five randomly selected images of each section were used for quantification. CD31 quantification was performed by calculating CD31-positive tube number. CD68, CD86, and CD206 quantification was performed by calculating CD68-positive cell number.

For Picrosirius red staining, specimens from three animals $(n=3)$ were dewaxed in $100 \%$ xylene, followed by washing in $100 \%$ ethanol and PBS twice, and then were immersed in Picrosirius red (Sirius Red $0.1 \%$ in picric acid) for $1 \mathrm{~h}$ at room temperature. After washing in PBS, sections were rapidly dehydrated, cleared in xylene, and mounted. Collagen fibres were detected by light and polarised light microscopy (Olympus, Hamburg, Germany). Under polarised light microscopy, collagen I (COL 1) fibres were stained red, whereas collagen III (COL 3) fibres appeared green. Images were analysed using Image-Pro Plus 6 software (Rockville, MD, USA) as previously described [20]. To define the pixel count, ranges were selected in the red, green, and blue channels, and then through trial and error, we selected the colour green or red and calculated the area of each collagen type in one field. Five random fields were selected from each sample for statistical analysis.

\section{Cell viability assay}

Briefly, 1000 cells ( $\mathrm{HaCaT}$ and human fibroblasts) were suspended in $100 \mu \mathrm{L}$ culture medium, seeded in 96-well plates, and cultured for $24 \mathrm{~h}$. Thereafter, cells were separately treated with hADSC-CM and hFDSPC-CM at six concentrations: $0,5,10,20,50$, and $100 \mu \mathrm{g} / \mathrm{mL}$, followed by culture for $72 \mathrm{~h}$. The cell viability assay was performed using cell counting kit-8 (CCK-8; Dojindo, 
Japan) according to the manufacturer's instructions. Briefly, $10 \mu \mathrm{L}$ CCK-8 solution was added to each well and incubated for $2.5 \mathrm{~h}$ at $37^{\circ} \mathrm{C}$. Next, the medium was harvested and measured at $450 \mathrm{~nm}$ using a microplate reader (Thermo Electron Corporation, Finland). All assays were repeated three times.

\section{EdU incorporation assay}

$\mathrm{HaCaT}$ and human fibroblasts were seeded in 96-well plates (2000 cells per well) and incubated at $37^{\circ} \mathrm{C}$ for $24 \mathrm{~h}$. Cells were treated with or without hADSC-CM and $\mathrm{hFDSPC}-\mathrm{CM}$ at a concentration of $20 \mu \mathrm{g} / \mathrm{mL}$ and continuously cultured for $72 \mathrm{~h}$. Cells were treated with 5-ethynyl20-deoxyuridine (BeyoClick ${ }^{\mathrm{mw}}$ EdU Cell Proliferation Kit with Alexa Fluor 488) at a working concentration of $50 \mu \mathrm{M}$ in $100 \mu \mathrm{L}$ culture medium for $2 \mathrm{~h}$. Then, cells were washed twice with PBS for 10 min and fixed with $4 \%$ paraformaldehyde for $15 \mathrm{~min}$ at room temperature, followed by incubation with $0.5 \%$ Triton X-100 (Sigma). Cells were then counterstained with DAPI (1:1000, Boster, Wuhan, China) and imaged under a fluorescent microscope (Olympus, Tokyo, Japan). Five randomly selected fields from each well were imaged, and the EdU-positive cells were calculated using Image-Pro Plus 6 software (Rockville, MD, USA).

\section{Scratch assay}

Migration of $\mathrm{HaCaT}$ and human fibroblasts was measured using the monolayer wound assay in vitro. Cells were plated in 6-well plates $\left(1 \times 10^{5}\right.$ cells per well) with culture medium until completely confluent. Cells were scraped across the plate with a $200-\mu \mathrm{L}$ pipette tip. Cells were cultured with serum-free DMEM with or without hADSC-CM and hFDSPC-CM $(20 \mu \mathrm{g} / \mathrm{mL})$ for $24 \mathrm{~h}$. Cell migrations at 0 and $24 \mathrm{~h}$ were imaged with inverted microscopy (Olympus, Tokyo, Japan), and five randomly selected fields from each well were used for scratch area calculation using Image-Pro Plus 6 software. The results are presented as scratch area at $0 \mathrm{~h}-$ scratch area at 24 $\mathrm{h}\left(\mu \mathrm{m}^{2}\right)$.

\section{Real-time-qPCR (RT-qPCR)}

Total RNA was extracted from cells using TRIzol $^{\circ}$ reagent (Invitrogen, Carlsbad, USA), followed by treatment with DNase I (Promega Corp., Madison, USA). cDNA was synthesised using a high-capacity cDNA synthesis kit (Takara Bio, Inc., Tokyo, Japan) according to the manufacturer's instructions. RT-qPCR was performed to determine mRNA levels using SYBR-Green I (Takara Bio, Inc. Otsu, Japan). The thermal cycling parameters were $95^{\circ} \mathrm{C}$ for 1 min, followed by 40 cycles at $95^{\circ} \mathrm{C}$ for $10 \mathrm{~s}$, and $60^{\circ} \mathrm{C}$ for $40 \mathrm{~s}$. The expression levels of genes were normalised to $\beta$ actin housekeeping gene expression. The primers used for real-time qPCR analysis are listed in Table 1.

\section{Western blot analysis}

Human fibroblasts were seeded into 6-well plates $\left(2 \times 10^{5}\right.$ cells $/ \mathrm{ml}$ ) and cultured with or without hADSC-CM and hFDSPC-CM at a concentration of $20 \mu \mathrm{g} / \mathrm{mL}$ for $48 \mathrm{~h}$. After removal of the medium, cells were washed with PBS twice, and then lysed using RIPA Lysis Buffer (Beyotime, Shanghai, China) with $1 \mathrm{mM}$ phenylmethanesulfonyl fluoride (PMSF, Beyotime, Shanghai, China). The lysates were collected and centrifuged at $14,000 \times g$ at $4{ }^{\circ} \mathrm{C}$ for 5 min. The supernatant protein concentration was quantified using a BCA Protein Assay Kit (Beyotime, Shanghai, China, Cat: P0012S) according to the instructions. The prepared protein was subjected to SDS-PAGE and subsequently transferred onto PVDF membranes. The PVDF membrane was blocked with $5 \%$ non-fat powdered milk in Tris-buffered solution plus Tween-20 (TBST) for $2 \mathrm{~h}$ at $37^{\circ} \mathrm{C}$. Membranes were then incubated overnight at $4{ }^{\circ} \mathrm{C}$ with primary antibodies, followed by incubation with appropriate HRP-conjugated secondary antibodies (Jackson ImmunoResearch, Madison, USA, Cat:111-035-003). The protein bands were visualised using an enhanced chemiluminescence (ECL) detection kit (Amersham Pharmacia Biotech, Piscataway, USA). The primary antibodies, including COL1 (Cat: ab138492), COL3 (Cat: ab184993), fibronectin (FN, Cat: ab2413), $\alpha$-SMA (Cat: ab124964), and transforming growth factor-beta 1 (TGF- $\beta 1$, Cat: ab215715), were purchased from Abcam (Cambridge, UK). Primary antibodies, including phospho-Smad2 (Cat: 18338), phospho-Smad3 (Cat: 9520), and Smad2/3 (Cat: $5678 \mathrm{~s}$ ) were purchased from Cell Signalling Technology (CST, NY, USA). The primary antibody for $\beta$-actin was purchased from Sigma-Aldrich (Missouri, USA, Cat: ZRB1312).

\section{Immunofluorescence staining}

Human fibroblasts were seeded $\left(1 \times 10^{5}\right.$ cells $\left./ \mathrm{mL}\right)$ and cultured with or without hADSC-CM and hFDSPC-CM $(20 \mu \mathrm{g} / \mathrm{mL})$ for $48 \mathrm{~h}$. Cells were then washed thrice with PBS and fixed with $4 \%$ paraformaldehyde for $15 \mathrm{~min}$ at room temperature. After nonspecific antigen blocking using goat serum (Beyotime, Shanghai, China), cells were incubated with COL 1(Cat:ab138492), COL 3 (Cat: ab237238), FN (Cat: ab45688), and $\alpha$-SMA (Cat: ab124964) primary antibodies (1:250-1:1000, Abcam, Cambridge, UK) at $4{ }^{\circ} \mathrm{C}$ overnight, followed by incubation with secondary antibodies (1:150; Santa Cruz Biotechnology, Inc., CA, USA, Cat: sc-516248) for $1 \mathrm{~h}$ at $37^{\circ} \mathrm{C}$. Images were captured using an inverted fluorescence microscope, and five randomly selected pictures were used to calculate positive cell numbers.

\section{ELISA assay}

After $72 \mathrm{~h}$ of incubation with or without hADSC-CM and hFDSPC-CM $(20 \mu \mathrm{g} / \mathrm{mL})$ in serum-free culture 
Table 1 Primer sequences used for real-time qPCR

\begin{tabular}{|c|c|c|c|}
\hline Gene & Species & Forward primer & Reverse primer \\
\hline ALP & Human & TACAAGCACTCCCACTTCATC & AGACCCAATAGGTAGTCCACAT \\
\hline BMP-2 & Human & GAAGAACTACCAGAAACGAGTG & GGTGATGGAAACTGCTATTG \\
\hline Osx & Human & CAGTTGATAGGGTTTCTCTTGTA & CATAGGACTTGAGGTTTCACAG \\
\hline OCN & Human & CTGTGACGAGTTGGCTGAC & AGCAGAGCGACACCCTAGA \\
\hline OPN & Human & CATTCCGATGTGATTGATAGTC & CTTCCTTACTITTGGGGTCTAC \\
\hline C/EBP a & Human & CCCTCAGCCTTGTTTGTACT & AAAATGGTGGTTTAGCAGAGA \\
\hline FABP4 & Human & AGAGAAAACGAGAGGATGATAA & TTCAATGCGAACTTCAGTC \\
\hline PPAR- $\gamma 2$ & Human & GCAGTGGGGATGTCTCATAAT & CAGCGGACTCTGGATTCAG \\
\hline SREBP1 & Human & AACACAGCAACCAGAAACTCA & GTCCTCCACCTCAGTCTTCAC \\
\hline $\mathrm{COL} 2$ & Human & TGGACGCCATGAAGGTITCT & TGGGAGCCAGATTGTCATCTC \\
\hline Aggrecan & Human & GTGCCTATCAGGACAAGGTCT & GATGCCTITCACCACGACTTC \\
\hline SOX-9 & Human & AGCGAACGCACATCAAGAC & CTGTAGGCGATCTGTTGGGG \\
\hline COL 1 & Human & AGGGCCAAGACGAAGACATC & GTCGGTGGGTGACTCTGAGC \\
\hline COL3 & Human & AAGGGCAGGGAACAACT & ATGAAGCAGAGCGAGAAG \\
\hline MMP-1 & Human & GGAGCTGTAGATGTCCTTGGGGT & GCCACAACTGCCAAATGGGCTT \\
\hline MMP-3 & Human & AGGACAAAGCAGGATCACAGTTG & CCTGGTACCCACGGAACCT \\
\hline FN & Human & TCTCCTGCCTGGTACAGAATAT & GGTCGCAGCAACAACTTCCAGGT \\
\hline a-SMA & Human & GCTACTCCTTCGTGACCACAG & GCCGTCGCCATCTCGTTCT \\
\hline TGF- $\beta 1$ & Human & TACTACGCCAAGGAGGTCAC & GAGAGCAACACGGGTTCAG \\
\hline$\beta$-actin & Human & GGCACTCTTCCAGCCTTCC & GAGCCGCCGATCCACAC \\
\hline
\end{tabular}

medium, TGF- $\beta 1$ protein from human fibroblasts was measured using a Human TGF- $\beta 1$ ELISA kit (ExCell Bio. Shanghai, China) according to the manufacturer's instructions. All assays were performed three times.

\section{Tube formation assay}

HUVECs $\left(1 \times 10^{4} /\right.$ well $)$ were suspended in DMEM supplemented with $10 \% \mathrm{FBS}$, and then seeded onto Matrigel-coated 96-well plates with or without hADSC-CM and hFDSPC-CM $(20 \mu \mathrm{g} / \mathrm{mL})$. The plate was incubated at $37{ }^{\circ} \mathrm{C}$ in $5 \% \mathrm{CO}_{2}$ for $6 \mathrm{~h}$. Tube formation was photographed under a light microscope (Carl Zeiss, Oberkochen, Germany). The number of junctions was calculated using Image software $(\mathrm{NIH}$, Bethesda, MD, USA).

\section{Statistical analysis}

Statistical analyses were performed using GraphPad Prism6 software (La Jolla, USA). Student's unpaired $t$ test was performed for two-group comparisons; one-way analysis of variance (ANOVA) was used for multiple group comparisons. All values in this study are presented as mean \pm standard deviation. A probability $(p)$ value $<0.05$ was considered significant.

\section{Results}

Identification of hFDSPCs and hADSCs

Passages 1-3 of hFDSPCs were cultured and formed compact and circular colonies. With increased cell passage (Fig. 1a), cell morphology gradually appeared more spindle-like (Fig. 1c), and colony formation number decreased, but remained above $30(\mathrm{P} 1=69.50 \pm 5.54, \mathrm{P} 2=$ $48.67 \pm 4.72, \mathrm{P} 3=36 \pm 5.40, n=6)$ (Fig. 1b). Flow cytometry results showed that hFDSPCs positively expressed CD90 (97.53\% \pm 0.48\%), CD44 (97.28\% \pm $0.52 \%), \quad$ CD105 (22.57\% $\pm 2.09 \%), \quad$ CD29 (98.62\% \pm $1.18 \%), \mathrm{CD} 13(98.06 \% \pm 0.26 \%)$, and CD59 $(98.80 \% \pm$ $1.02 \%)$, but negatively expressed CD34 (1.30\% $\pm 0.75 \%)$, CD45 (0.73\% $\pm 0.39 \%), \operatorname{CD} 31(2.07 \% \pm 0.31 \%)$, and CD133 (0.88\% $\pm 0.16 \%)$ (Fig. $1 d)$.

Passage 2 hFDSPCs showed osteogenic (Fig. 2a, b), adipogenic (Fig. 2c, d), and chondrogenic (Fig. 2e, f) differentiation potential. The elevated osteogenic (ALP, BMP2, Osx, OCN, OPN), adipogenic (C/EBP $\alpha$, FABP4, PPAR- $\gamma 2$, SREBP1), and chondrogenic (COL2, Aggrecan, SOX-9) mRNA expression confirmed the trilineage differentiation results. In addition, in the chondrogenic differentiation assay, no pellet was formed in the control group during the culture process.

Passage 3 hADSCs showed high-level expression of hADSC surface markers, such as CD73 (97.97\% $\pm 1.19 \%)$, 


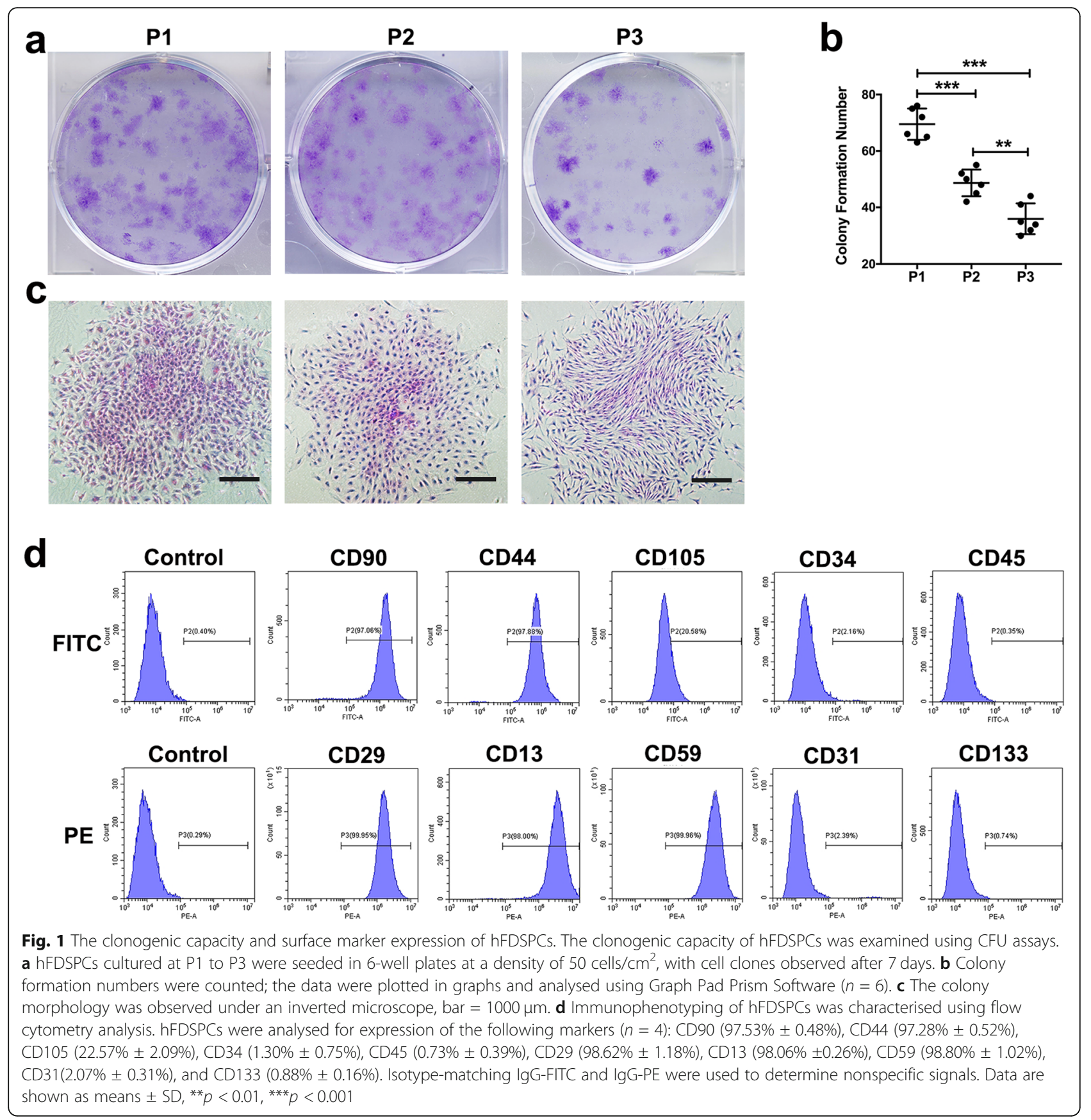

CD90 (97.03\% $\pm 1.45 \%)$, and CD105 (97.04\% $\pm 1.12 \%)$, but almost no expression of negative markers, such as CD19 $(1.17 \% \pm 0.69 \%), \mathrm{CD} 34(0.83 \% \pm 0.35 \%), \mathrm{CD} 11 \mathrm{~b}(1.50 \% \pm$ $0.86 \%)$, CD $45(0.99 \% \pm 0.54 \%)$, and HLA-DR $(1.20 \% \pm$ $0.45 \%$ ) (Fig. S1).

\section{hFDSPC-CM promoted wound healing in $\mathrm{db} / \mathrm{db}$ mice}

During the wound healing process, the wounds in all groups remained clean and dry with few exudates, blood scabs, and no obvious contraction. The HA hydrogel or hydrogel mixture was observed to be gradually absorbed within $48 \mathrm{~h}$. Regarding the wound area, HA treatment, hADSC-CM + HA, and hFDSPC-CM + HA groups showed significantly decreased wound area compared to the control group from day 3 to day $14(p<0.05)$. Furthermore, the hFDSPC-CM + HA group showed significantly decreased wound area compared to the HA group from day 7 and significantly decreased the wound area compared to the hADSC-CM group from day 10 (Fig. 3a, b) $(p<0.05)$. The results demonstrated that HA combined with hFDSPC-CM exhibited the best curative effect in promoting wound healing over time. 


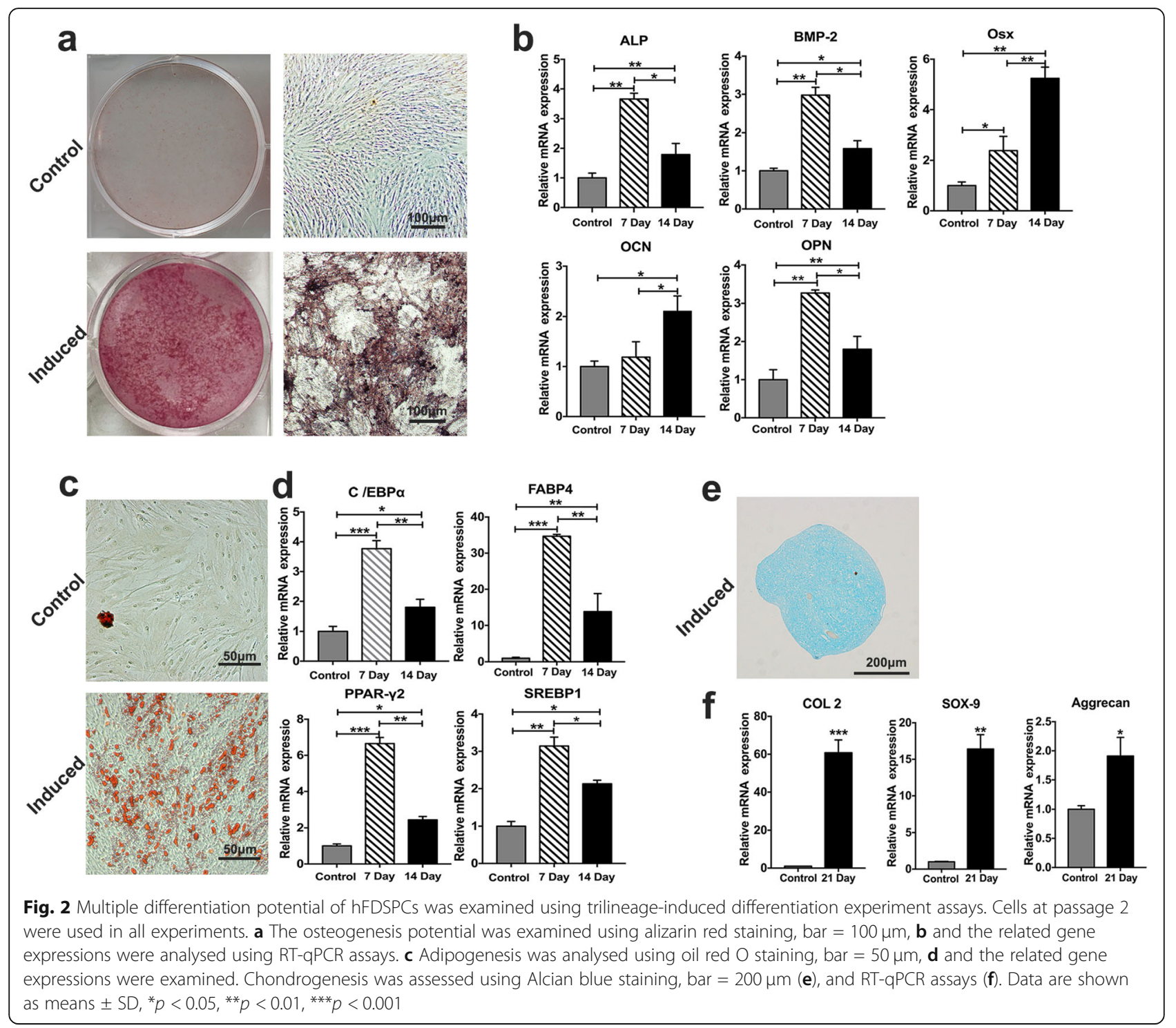

Regarding wound healing time, all treatment groups showed significantly accelerated wound healing compared to the control group $(p<0.05)$. Further, the HA + hFDSPC-CM group exhibited the shortest wound healing time $(13.80 \pm 0.84$ days $)$ compared to the control group (22.6 \pm 1.14 days), as well as the HA group (17.80 \pm 0.84 days $)$ and HA + hADSC-CM group $(15.8 \pm 1.30$ days) (Fig. 3c).

\section{Assessment of the effect of hFDSPC-CM on re- epithelialisation, angiogenesis, and anti-inflammation in $\mathrm{db} / \mathrm{db}$ mice wound}

Granulation tissue formation and re-epithelialisation on day 14 was visualised using HE staining (Fig. 4a, b). Histological observations showed that there was almost no epidermis in the control group, while little reepithelialisation could be observed at the edge of the wound in the HA group. The newly formed tissue in the hADSC-CM + HA group was almost intact, but the epidermal tissue remained discontinuous. In contrast, the wound tissue in the hFDSPC-CM + HA group already showed intact and thinner epithelium in comparison to other groups.

Wound angiogenesis was assessed using CD31 staining (Fig. 4c). Compared to the control group, all other groups showed increased microvessels in the granulation tissue at day $14(p<0.001)$. Besides, both hFDSPC-CM + HA group and hADSC-CM + HA group showed increased microvessel density compared to the HA group $(p<0.01)$. However, no significant difference was observed between the hADSC-CM + HA and hFDSPC-CM + HA groups (Fig. 4d). These results indicate that hFDSPC-CM exerts a similar effect on wound angiogenesis as hADSC-CM in diabetic mice. 


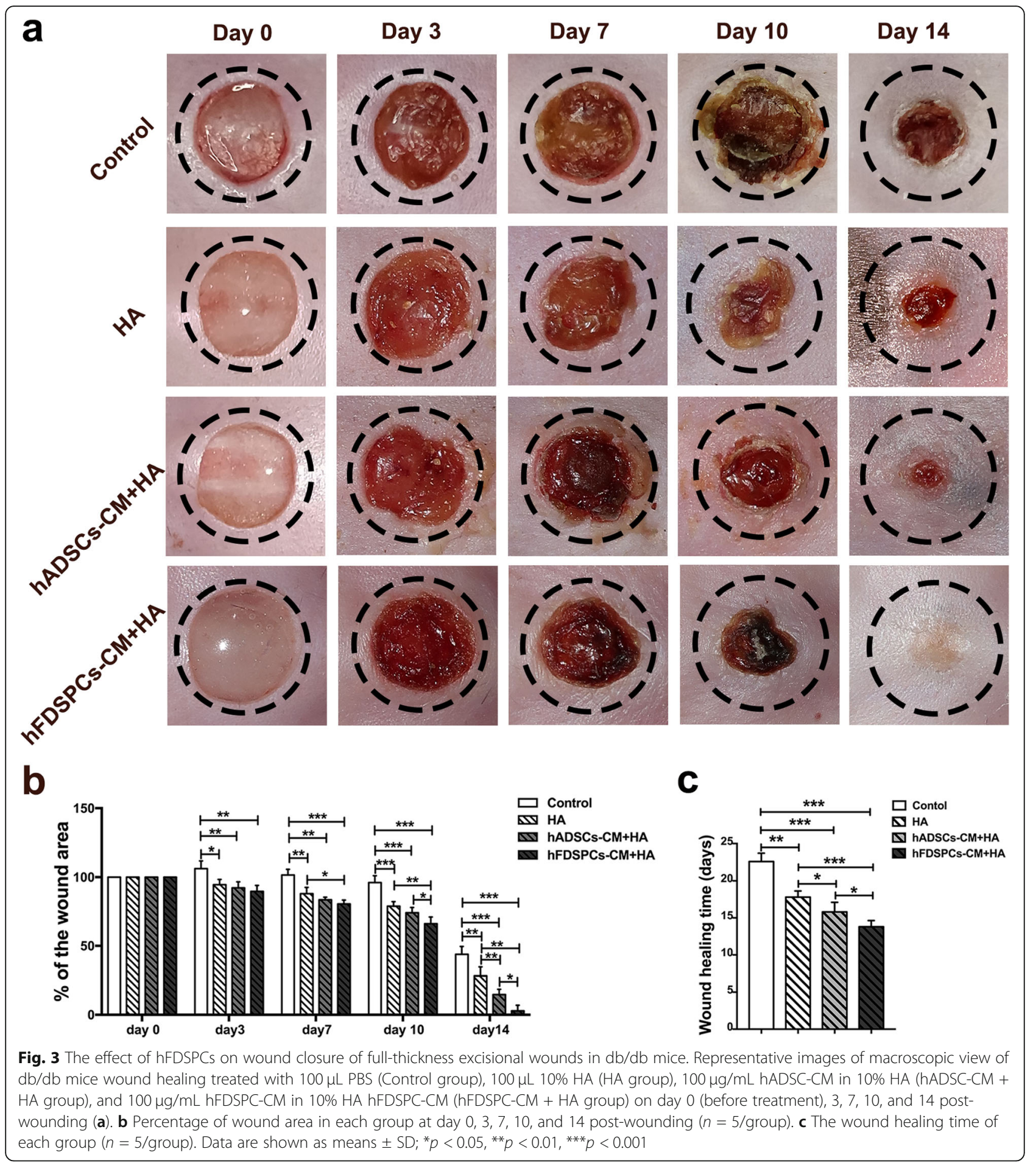

Macrophages stained for CD68 (general macrophages), CD86 (M1 type macrophages), and CD206 (M2 type macrophages) were used to evaluate inflammatory cell infiltration and macrophage polarisation (Fig. 4e, g, i). Compared to the control group, all treatment groups showed significantly decreased CD68-positive cells $(p<$ 0.05). In addition, both the hFDSPC-CM + HA and
hADSC-CM + HA groups showed significantly decreased CD68-positive cells compared to the HA group $(p<0.01)$. Furthermore, the hFDSPC-CM + HA group showed the least CD68-positive cells compared with the other groups (Fig. 4f). In the hFDSPC-CM + HA and hADSC-CM + HA groups, CD86-positive cells significantly decreased $(p<0.001)$, while CD206-positive cells 


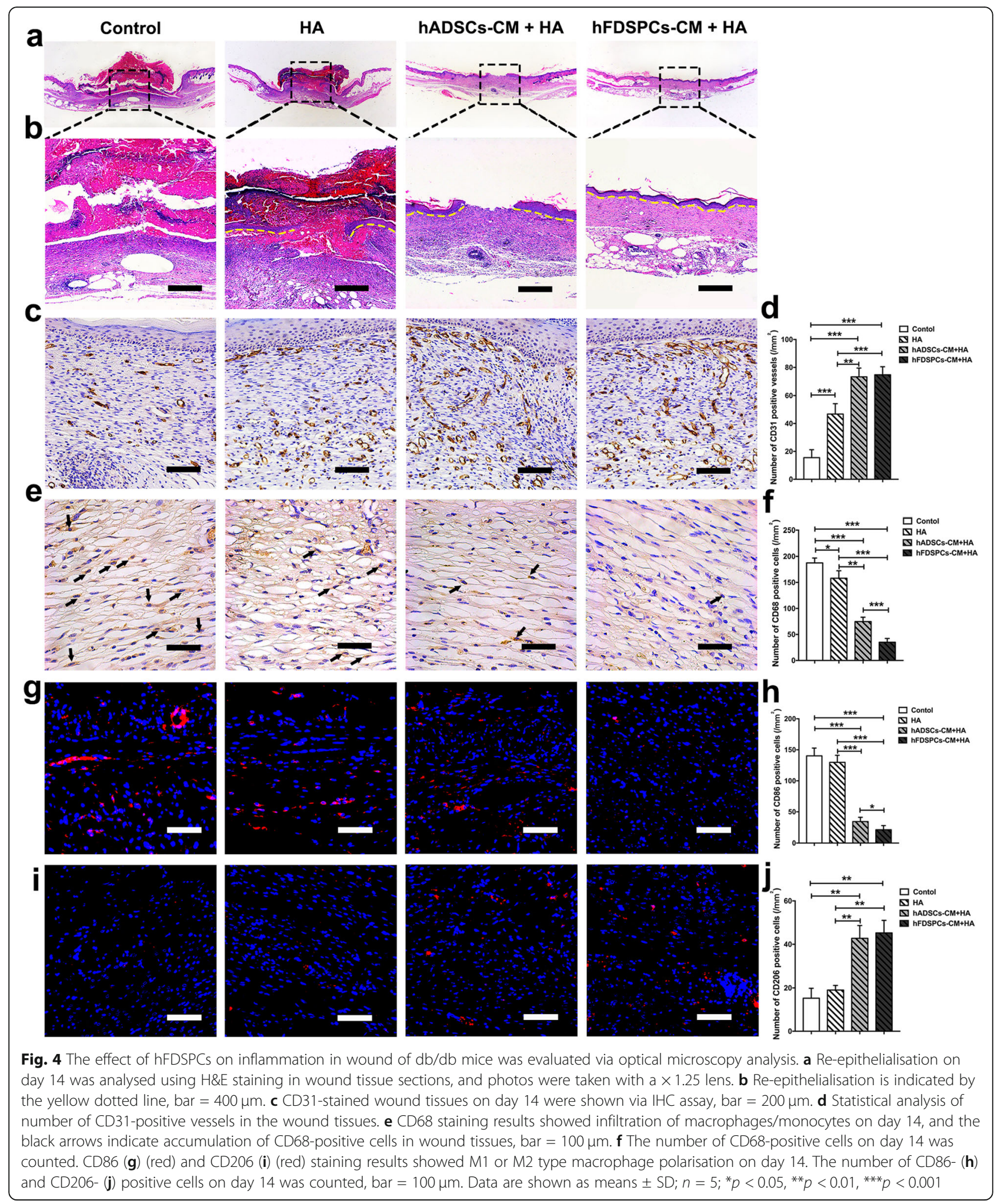

significantly increased $(p<0.01)$ compared to those in the HA and control group. The HA group showed no significant difference in CD86- and CD-206 positive cells compared to the control group $(p>0.05)$. However, the
hFDSPC-CM+ HA group showed less CD86-positive cells $(p<0.05)$, but comparable CD206-positive cells ( $p$ $>0.05)$ when compared with the hADSC-CM + HA group (Fig. $4 \mathrm{~h}, \mathrm{j}$ ). These results indicate that hFDSPC- 
CM inhibited excessive inflammation and increased anti-inflammation response in diabetic wound healing processes.

hFDSPC-CM enhanced collagen regeneration, maturation, and remodelling in $\mathrm{db} / \mathrm{db}$ mouse wounds

The regeneration of dermis in diabetic wounds is mainly assessed by collagen regeneration and remodelling through Masson's trichrome staining and Picrosirius red staining. As shown in Fig. 5a, the Masson's trichrome staining results were similar to HE staining results in each group on day 14. Newly formed sparse collagen tissue components were found in the control group. In the HA group, collagen formation increased but the dermis layer remained incomplete. By contrast, both the hFDSPC-CM + HA and hADSC-CM + HA groups showed more collagen synthesis than the HA and control groups $(p<0.01)$ (Fig. $5 \mathrm{~b})$. Further, the hFDSPC$\mathrm{CM}+\mathrm{HA}$ group exhibited the greatest collagen synthesis and most orderly collagen arrangement (Fig. 5c).
As the results showed, in the control and HA group, collagen $\mathrm{I} / \mathrm{III}$ ratio was less than 0.5 (collagen $\mathrm{I} / \mathrm{II}=0.13$ \pm 0.03 and $0.18 \pm 0.07$, respectively in the control and HA groups), with no significant difference between the two groups $(p>0.05)$. However, both the hFDSPC-CM $+\mathrm{HA}$ and hFDSPC-CM + HA groups showed significantly increased collagen I/III ratio (collagen I/II $=1.35$ \pm 0.19 and $2.63 \pm 0.19$, respectively) $(p<0.001)$. Furthermore, the hFDSPC-CM + HA group exhibited a higher ratio than the hADSC-CM + HA group, indicating that hFDSPC-CM mainly promoted collagen I expression rather than collagen III expression (Fig. 5b, d).

\section{hFDSPC-CM promoted cell proliferation of HaCaT cells and human fibroblasts in vitro}

To explain the mechanism of hFDSPC-CM in promoting wound re-epithelialisation and collagen synthesis, which were mainly attributed to epidermal cells and dermis cell biological activity, $\mathrm{HaCaT}$ cells and human fibroblasts were treated with various concentrations of hFDSPC-CM or hADSC-CM $(0,5,10,20,50,100 \mu \mathrm{g} / \mathrm{mL})$ for $72 \mathrm{~h}$.

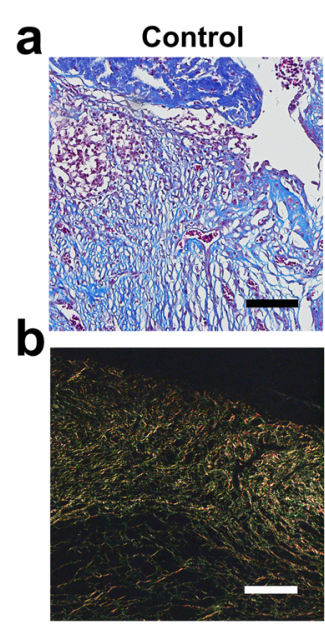

C
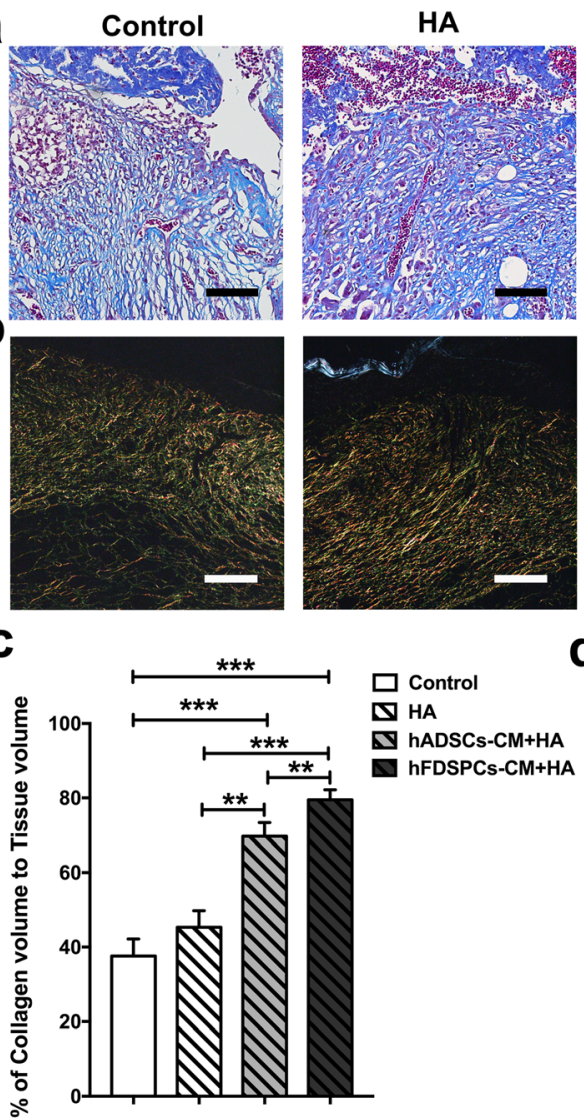
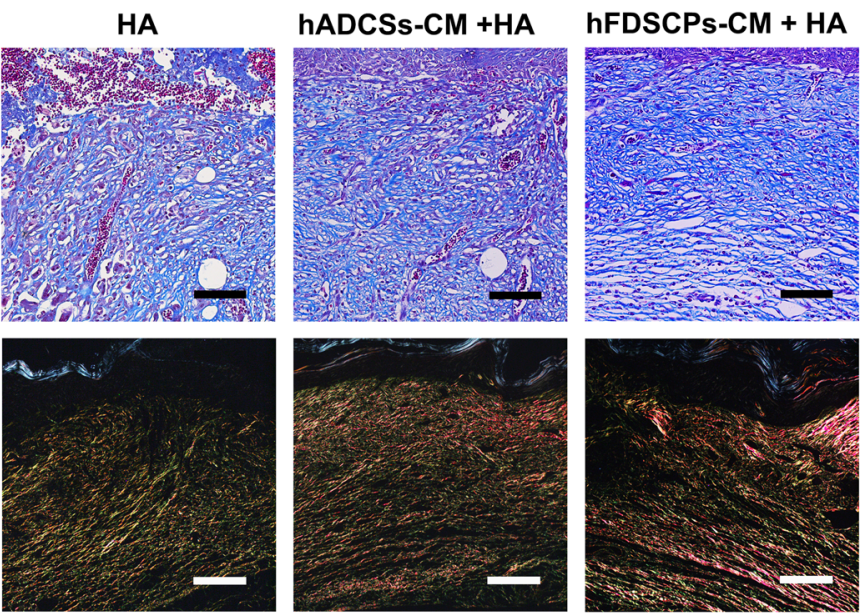

d

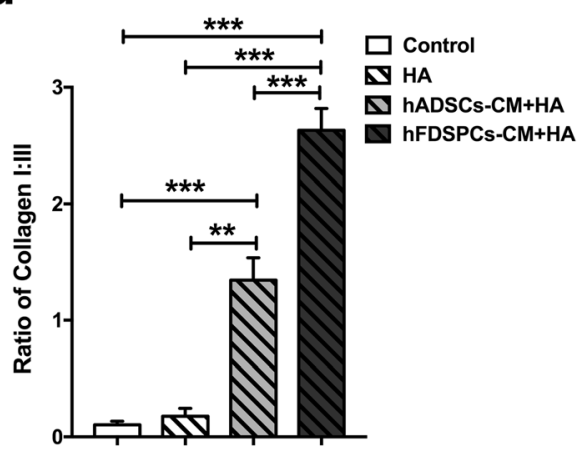

Fig. 5 Effect of hFDSPC-CM on collagen regeneration, maturation, and remodelling in wounds of db/db mice. a Masson staining for representative wound beds on day 14; collagen deposition is stained blue, bar $=200 \mu \mathrm{m}$. b Regenerated collagen content was analysed using Picrosirius red staining under a polarised light microscope. Collagen type III is visualised in green colour and collagen type I is visualised in orange/red colour, bar $=400 \mu \mathrm{m}$. c The percentage of collagen volume to tissue volume was quantified according to the Masson staining results. d Ratio of collagen I:III in wound beds of each group. Data are shown as means $\pm \mathrm{SD} ; n=4$; ${ }^{* *} p<0.01,{ }^{* * *} p<0.001$ 
CCK-8 cell activity (metabolic activity) assay results showed that both hFDSPC-CM and hADSC-CM promoted $\mathrm{HaCaT}$ cell/human fibroblast activity in a dosedependent manner (Fig. 6a, b). For HaCaT cells, hFDSPC$\mathrm{CM}$ exhibited an improved effect in promoting cell activity compared to hADSC-CM at $20 \mu \mathrm{g} / \mathrm{mL}$ and $100 \mu \mathrm{g} / \mathrm{mL}$ $(p<0.05)$. For human fibroblasts, hFDSPC-CM promoted cell activity compared to hADSC-CM in all treatment groups $(p<0.05)$. Based on the above results, $20 \mu \mathrm{g} / \mathrm{mL}$ was chosen as an effective concentration to perform the following in vitro experiments. EdU assay results indicated that $\mathrm{HaCaT}$ cell/human fibroblasts significantly proliferated compared to the control group $(p<0.01)$ after $72 \mathrm{~h}$ of incubation with hFDSPC-CM and hADSC-CM, and hFDSPC-CM exerted stronger effects on the proliferation of both $\mathrm{HaCaT}$ cells and human fibroblasts $(p<0.05)$.

\section{HFDSPC-CM promoted cell migration of $\mathrm{HaCaT}$ and} human fibroblasts in vitro

After incubation with $20 \mu \mathrm{g} / \mathrm{mL}$ hFDSPC-CM/hADSC$\mathrm{CM}$ for $24 \mathrm{~h}$, the migration area of $\mathrm{HaCaT}$ cells and human fibroblasts significantly increased in the hFDSPC-
CM and hADSC-CM group, compared to that in the control group (Fig. 7). Regarding human fibroblasts, the hFDSPC-CM group demonstrated a larger migration area than the hADSC-CM group $(p<0.05)$ (Fig. 7d). However, no significant difference was observed in $\mathrm{HaCaT}$ cell migration between the hFDSPC-CM and hADSC-CM groups ( $p>0.05)$ (Fig. 7b).

HFDSPC-CM promotes tube formation of HUVECs in vitro In vitro, hFDSPC-CM and hADSC-CM significantly promoted tube formation compared to the control group. However, no significant difference was observed between the hFDSPC-CM and hADSC-CM groups $(p>0.05)$, which indicates that hFDSPC-CM and hADSC-CM display equal efficiency in promoting tube formation of HUVECs (Fig. S2).

\section{HFDSPC-CM promotes extracellular matrix (ECM)} production of human fibroblasts by activating TGF- $\beta$ / Smad pathways in vitro

We observed that hFDSPC-CM enhanced wound collagen synthesis, maturation, and remodelling, the mechanism of which may be attributed to fibroblast functions.

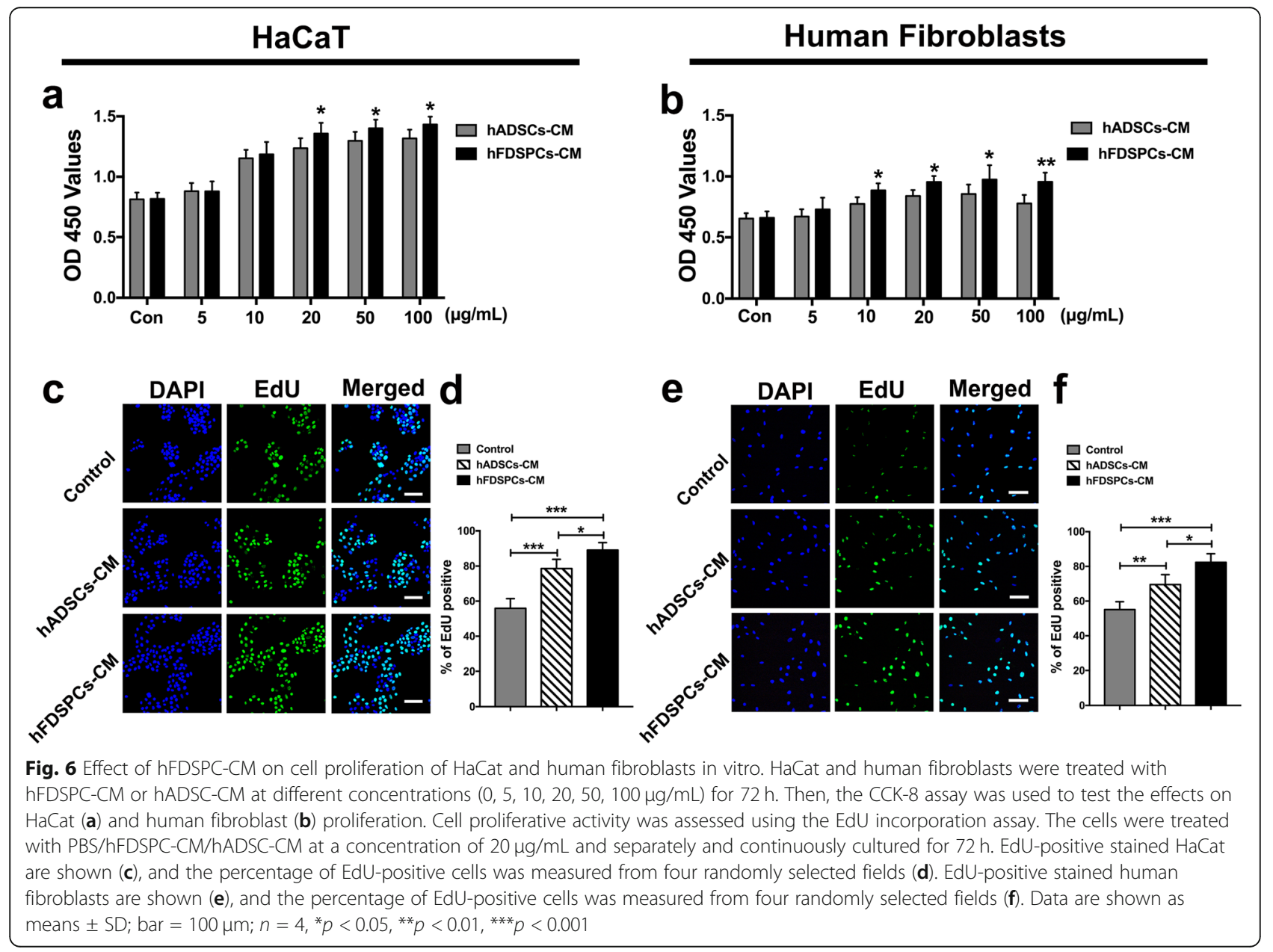




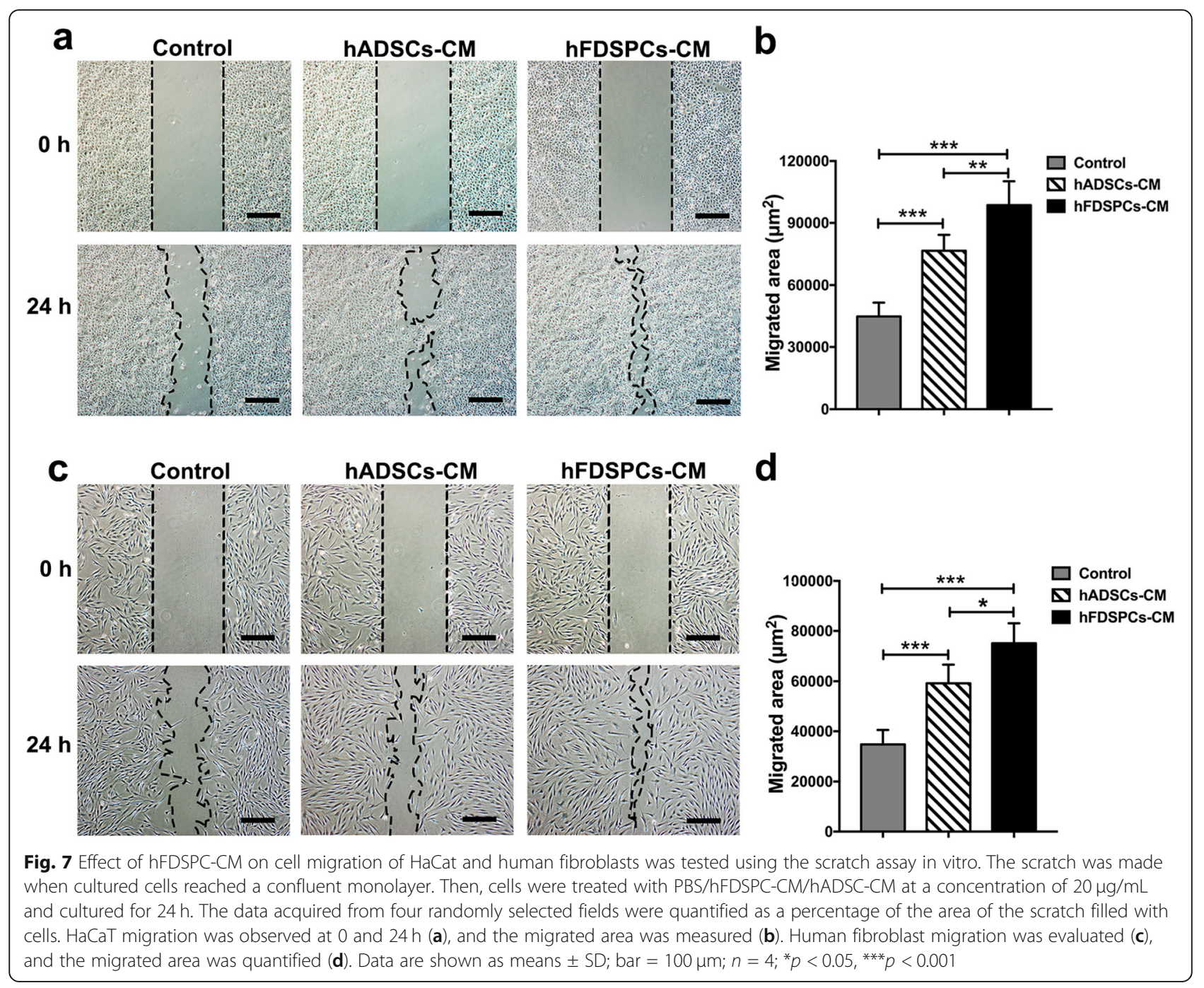

Thus, human fibroblasts were incubated with hFDSPC-CM for $48 \mathrm{~h}$ and the functions related to the dynamic balance of extracellular matrix metabolism were analysed. mRNA and protein expression results showed that hADSC-CM and hFDSPC-CM significantly promoted ECM marker production, such as COL1, COL3, and FN. hFDSPC-CM demonstrated improved promotion of markers compared with hADSCCM (Fig. 8a, b, c, i, j). Meanwhile, compared to the control group, both hADSC-CM and hFDSPC-CM significantly decreased matrix metalloproteinases 3 (MMP-3), which plays a role in ECM degradation $(p<0.01)$. Significantly decreased MMP-3 expression was also observed in the hFDSPC-CM group compared to the hADSC-CM group. hFDSPC-CM rather than hADSC-CM significantly decreased matrix metalloproteinases 1 (MMP-1) expression compared to the control group $(p<0.05)$.

$\alpha$-SMA as a marker of myofibroblasts, which contract the wound to accelerate wound healing, was also detected. mRNA and protein expression results showed that hFDSPC-CM and hADSC-CM significantly increased $\alpha$-SMA expression. Meanwhile, greater $\alpha$-SMA expression was observed in the hFDSPC-CM group than in the hADSC-CM group.

The TGF- $\beta 1 /$ Smad signalling pathway is pivotal for fibroblast differentiation and ECM deposition in wound healing [21]. Hence, based on the above results, we further investigated whether TGF- $\beta 1 / \mathrm{Smad}$ signalling in human fibroblasts was unregulated under hFDSPC-CM exposure. Firstly, hFDSPC-CM increased TGF- $\beta 1$ transcript and extracellular secretion in comparison with other groups (Fig. 8g, h). Moreover, western blot analysis showed that hFDSPC-CM increased the expression of TGF- $\beta 1$ and phosphorylation levels of Smad 2 and Smad 3 in a dose-dependent manner (Fig. 8k). These observations suggested that both TGF- $\beta /$ Smad pathways were activated in human fibroblasts exposed to hFDSPC-CM.

Taken together, these data revealed that hFDSPCs can promote collagen production of human fibroblasts through TGF- $\beta /$ Smad pathways. 


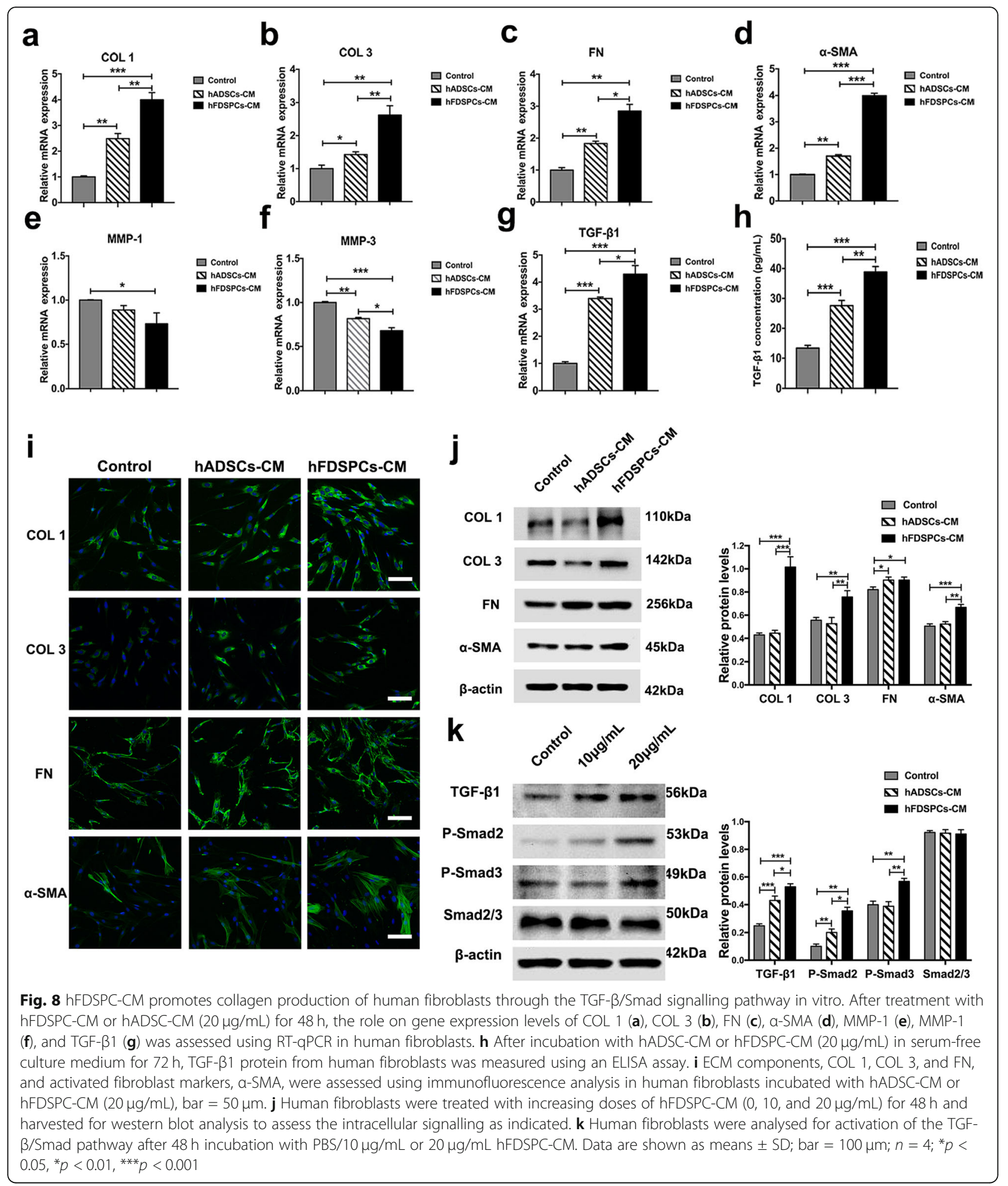

\section{Discussion}

As a biological waste, human foreskin is a reservoir of abundant dermal stem/progenitor cells with potential therapeutic value. However, no research has investigated the use of hFDSPC-CM to facilitate diabetic wound healing. Although HA can be used as a practical wound dressing, therapies that integrated HA with other components such as exosomes and silver particles exhibited enhanced healing effects [16, 17]. Thus, hFDSPC-CM was mixed with HA hydrogel to endow $\mathrm{HA}$ with 
bioactivity in this study. We mainly focused on enriching HA hydrogel and endowing it with definite bioactivity compared with some previous studies that focused on controlling the mechanical strength, gelation time, and drug release of HA hydrogels [22-24].

In our current study, we successfully isolated hFDSPCs from human foreskin tissue. They exhibit the characteristics of MSCs. Although some extracellular vesicles and proteins were removed in the process of preparing condensed CM (some large extracellular vesicles larger than $220 \mu \mathrm{m}$ have been removed in the process of filtration cell supernatants through a $0.22-\mu \mathrm{m}$ filter; some small extracellular vesicles and protein have been removed in the process of centrifugation with a cut-off value of 10 $\mathrm{kDa}$ ), our data revealed that hFDSPC-CM+HA accelerated cutaneous wound healing at a faster rate than did the hADSC-CM+HA treatment. The underlying mechanisms might promote epidermal proliferation and migration, acceleration of dermis closure and dermal collagen regeneration and remodelling, and inhibition of excessive inflammation.

The proliferative phase of wound healing is usually characterised by cell proliferation and migration in epidermal and dermal layers [25]. Keratinocyte migration from the wound edge is a crucial step in the reepithelisation of cutaneous wounds. Upon injury, keratinocytes migrate over the injured dermis to reepithelialise the damaged tissue and restore the epidermal barrier [25]. However, in a diabetic wound, the abnormal keratinocytes with obtuse migration and delayed proliferation lead to epidermis thickening at the wound edge, resulting in non-healing [26]. In the present study, complete re-epithelisation in wound tissue was observed in the hFDSPC-CM + HA-treated group, compared to the discontinuous and thickening epidermis in the other groups (Fig. 4a, b). To explain the ideal result of hFDSPC-CM + HA-treated group we observed, the in vitro assays showed hFDSPC-CM exhibited better effect to promote $\mathrm{HaCaT}$ proliferation and migration than did hADSC-CM (Fig. 6a, c, and d; Fig. 7a, b).

In addition to epidermal cells, fibroblasts in dermis also play an important role in skin wound healing. The rapid proliferation and migration of fibroblasts after injury determine the contraction and closure of the wound bed and the integrity of the newly formed dermis. However, fibroblast ability to proliferate and migrate is impaired in diabetic wounds compared with those in uninjured skin $[27,28]$. In vivo, a complete and wellorganised structure was observed in the hFDSPC-CMtreated wound tissue, but in other groups, the dermal tissue was relatively loose and irregular with numerous clots (Fig. 5a). To confirm the effect of hFDSPC-CM on fibroblasts, in vitro assays proved that hFDSPC-CMtreated human fibroblasts showed more active proliferative and migratory behaviours in vitro (Fig. 6b, e, and f; Fig. 7c, d).

Moreover, fibroblasts initiate collagen synthesis after migration to the wound site and are responsible for ECM deposition and remodelling. Wound ECM not only provides a support structure that facilitates cell migration, cell differentiation, and wound healing, but also serves as a reservoir for growth factors and mediates cell-cell, cell-matrix, and matrix-protein interactions [29, 30]. In the diabetic wound, the structure and function of ECM are considerably damaged by fibroblast dysfunction, abnormities in protein deposition, degradation, and remodelling [30]. Skin biopsies from diabetic patients exhibit lower expression of COL 1 and 3 [31], and the ratio of collagen I/III, which is closely related to ECM tensile strength, is also reduced [32]. Further, ECM in diabetic wounds exhibits anomalous structure, characterised by increased interstitial space between collagen fibres [33].

Surprisingly, our study demonstrated that hFDSPC-CM displayed a significant advantage in this process. The differentiation of fibroblasts into myofibroblasts is very important in collagen synthesis and deposition. Myofibroblasts reportedly secrete more collagen molecules, especially COL 1 , thereby inducing wound contraction [34]. In the present study, a higher expression ratio of collagen I/III was observed in the hFDSPC-CM + HA-treated group rather than the HA group, illustrating that hFDSPC-CM promoted ECM maturation and remodelling (Fig. 5b, d). Meanwhile, hFDSPC-CM-treated human fibroblasts expressed more $\alpha$ SMA, a marker of myofibroblasts [35] (Fig 8d, i, and j), explaining why these cells were more active in collagen secretion and deposition (Figs. 5 and 8). More evidence was found in the expression of matrix metalloproteinases, which are responsible for ECM degradation and remodelling [36] (Fig. 8e, f).

TGF- $\beta 1$ is a known inducer of fibroblast differentiation, and the TGF- $\beta$ / Smad signalling pathway plays a key role in promotion of synthesis, deposition, and organisation of collagen in wound healing [21, 35, 37]. We speculated whether the TGF- $\beta$ / Smad pathway also played an important role in the regulatory effect of hFDSPC-CM. Thus, we detected TGF- $\beta 1$ transcript expression levels and extracellular secretion. Our results indicated that hFDSPC-CM-treated fibroblasts expressed more TGF- $\beta 1$ than did both the control group and the hADSC-CM group (Fig. 8g, h). Western blot results further supported that TGF- $\beta /$ Smad signalling pathways were involved in this process (Fig. 8k). It is worth noting that excessive activation of TGF- $\beta /$ Smad signalling pathways and myofibroblasts is involved in pathological scar formation $[38,39]$. However, it is more likely that their activation is a physiological process in wound healing, considering that this process has been widely reported 
previously $[40,41]$. Nevertheless, we cannot rule out the possibility that hFDSPC-CM activates pathological scar formation. It is worth studying the effect of hFDSPC-CM on scar formation in the future in a rabbit ear scar model rather than mouse skin wound healing model, considering that no obvious scar forms on mouse skin [42].

Prolonged inflammation is observed in diabetic wounds with the persistence of excessive macrophages at the wound sites $[43,44]$. It has been reported that suppressing inflammation may increase collagen production and re-epithelialisation [45]. Our results showed that hFDSPC-CM treatment significantly reduced macrophage infiltration (CD68-positive cells) and promoted macrophage polarisation from M1 (CD86-positive cells) to M2 (CD206-positive cells) type macrophages in diabetic mouse wounds (Fig. $4 \mathrm{e}-\mathrm{j}$ ), suggesting its effect on anti-inflammation and promotion of skin regeneration in wound healing. This may also promote reepithelialisation and collagen synthesis and remodelling.

Another essential stage of wound healing is adequate perfusion through capillary networks, which is facilitated by angiogenesis [46]. In our study, hFDSPC-CM showed a similar ability to hADSC-CM in promotion of neovascularisation in vitro and in vivo (Fig. 4c, d; Fig. S2). These results also confirmed the effect of hFDSPC-CM in promoting skin wound healing.

In summary, hFDSPCs may present a novel alternative source for therapeutic use in diabetic wound healing. hFDSPC-CM endowed HA with good bioactivity for skin wound healing in multiple ways. It presents significant advantages in reducing inflammation, collagen synthesis, and remodelling compared with hFDSPC-CM. Although we observed the effect of hFDSPC-CM on diabetic wound healing, the precise active ingredients within it need to be further confirmed and the related regulatory mechanisms should be further explored. In addition, the immunogenicity and safety assays in this study are insufficient, and we will discuss these contents in detail in future studies for clinical application.

\section{Conclusions}

In comparison with hADSC-CM, hFDSPC-CM endowed HA with superior wound healing effects by accelerating diabetic wound closure and promoting wound closure rate. The underlying mechanism may contribute to promoting proliferation and migration of epidermal cells with fibroblasts, thus leading to ECM deposition and remodelling. Decreased inflammation may be attributed to the above phenomenon.

\section{Supplementary Information}

The online version contains supplementary material available at https://doi. org/10.1186/s13287-020-02116-5.
Additional file 1: Fig. S1. Identification of the characteristics of hADSCs. A trilineage-induced differentiation experiment to confirm multiple differentiation potential. The cells at passage 2 were used in all experiments. The osteogenesis potential was examined using alizarin red staining, bar $=100 \mu \mathrm{m}$ (a). Adipogenesis was analysed using oil red $\mathrm{O}$ staining, bar $=50 \mu \mathrm{m}$ (b). Chondrogenesis was assessed using alcian blue staining, bar $=200 \mu \mathrm{m}$ (c). Immunophenotyping of hADSCs was characterised using flow cytometry analysis (d). hADSCs were analysed for expression of the following markers: CD19 $(1.17 \% \pm 0.69 \%)$, CD34 $(0.83 \% \pm$ $0.35 \%)$, CD11b (1.50\% $\pm 0.86 \%)$, CD45 (0.99\% $\pm 0.54 \%)$, HLA-DR $(1.20 \% \pm$ $0.45 \%), \operatorname{CD} 73(97.97 \% \pm 1.19 \%), \operatorname{CD} 90(97.03 \% \pm 1.45 \%)$, and CD105 $(97.04 \% \pm 1.12 \%)$. Data are shown as means $\pm S D, n=4$. Fig. S2. Tube formation assay of HUVECs in vivo. (a) HUVECs treated with hADSC-CM or hFDSPC-CM $(20 \mu \mathrm{g} / \mathrm{mL})$ were evaluated after $6 \mathrm{~h}$, and the PBS treatment was used in the control group, bar $=25 \mu \mathrm{m}$. (b) Assessment of number of branches in each group. (c) Quantification of mean tube length. Data are shown as means $\pm S D ; n=4{ }^{* *} p<0.01,{ }^{* *} p<0.001$. Fig. S3. The test of hydrogel adhesion. The hydrogel sticked to the walls of the bottle without sliding down.

\section{Abbreviations}

DPSCs: Dermis-derived progenitor/stem cells; CM: Conditioned medium; HA: Hyaluronic acid; hFDSPCs: Human foreskin-derived dermal stem/progenitor cells; hFDSPC-CM: Human foreskin-derived dermal stem/progenitor cellconditioned medium; hADSCs: Human adipose-derived stem cells; hADSCCM: Human adipose-derived stem cell-conditioned medium; HUVECs: Human umbilical vein endothelial cells; ECM: Extracellular matrix; COL 1: Collagen I; COL 3: Collagen III; FN: Fibronectin; MMP-1: Matrix metalloproteinases 1; MMP-3: Matrix metalloproteinases 3; TGF- 31 : Transforming growth factorbeta 1; MSCs: Mesenchymal stem cells; EVs: Extracellular vesicles; HaCaT: Human immortal keratinocyte cells; HUVECs: Human vascular endothelial cells; HE: Haematoxylin and eosin

\section{Acknowledgements}

We would like to thank Editage (www.editage.cn) for English language editing.

\section{Authors' contributions}

YXZ conceived the study and designed the experiments. YXZ and ZZ provided funding for the study and revised the manuscript. $Y X$ and $P X$ performed the research, data analysis, and manuscript writing. XSW and YSC contributed to the analysis and interpretation of data. All authors read and approved the final manuscript for publication.

\section{Funding}

This study was supported by the national natural science foundation of China (81772098, 81801917), Outstanding Professional and Technical Leader Program of the Shanghai Municipal Science and Technology Commission (18XD1423700), Clinical Multi-Disciplinary Team Research Program of 9th People's Hospital, Shanghai Jiao Tong University School of Medicine (2017-1007), Clinical Research Program of 9th People's Hospital, Shanghai Jiao Tong University School of Medicine (JYLJ027), and Shanghai Municipal Education Commission Gaofeng Clinical Medicine Grant Support (20152227).

Availability of data and materials

The datasets generated during and/or analysed during the current study are available from the corresponding author on reasonable request.

Ethics approval and consent to participate

The study was conducted according to the guidelines set by the Ethics Committee of Shanghai 9th People's Hospital.

Consent for publication

Not applicable.

\section{Competing interests}

The authors declare that they have no competing interests.

\section{Author details}

${ }^{1}$ Department of Plastic and Reconstructive Surgery, Shanghai 9th People's Hospital, Shanghai Jiao Tong University School of Medicine, 639 Zhi Zao Ju 
Road, Shanghai 200011, China. ${ }^{2}$ Shanghai Tissue Engineering Key Laboratory, Shanghai Jiao Tong University School of Medicine, Shanghai 200011, China.

\section{Received: 20 June 2020 Accepted: 22 December 2020} Published online: 09 January 2021

\section{References}

1. Martin A, Komada MR, Sane DC. Abnormal angiogenesis in diabetes mellitus. ChemInform. 2003;34:175-45.

2. Jude EB, Blakytny R, Bulmer J, Boulton AJM, Ferguson MWJ. Transforming growth factor-beta 1, 2, 3 and receptor type I and II in diabetic foot ulcers. Diabet Med. 2002;19:440-7.

3. Liu Z, Dumville JC, Hinchliffe RJ, Cullum N, Game F, Stubbs N, et al. The Cochrane database of systematic reviews. 2018;10:CD010318.

4. Cavanagh PR, Lipsky BA, Bradbury AW, Botek G. Treatment for diabetic foot ulcers. Lancet. 2005;366:1725-35.

5. Everett $\mathrm{E}$, Mathioudakis N. Update on management of diabetic foot ulcers. Ann N Y Acad Sci. 2018;1411:153-65.

6. Moon K-C, Lee J-S, Han S-K, Lee H-W, Dhong E-S. Effects of human umbilical cord blood-derived mesenchymal stromal cells and dermal fibroblasts on diabetic wound healing. Cytotherapy. 2017;19:821-8.

7. Oh SJ, Marra KG, leraci M, Rubin JP, Grahovac T, Lin Y-C. Evaluation of a multi-layer adipose-derived stem cell sheet in a full-thickness wound healing model. Acta Biomater. 2013;9:5243-50

8. Maharlooei MK, Bagheri M, Solhjo Z, Jahromi BM, Akrami M, Rohani L, et al. Adipose tissue derived mesenchymal stem cell (AD-MSC) promotes skin wound healing in diabetic rats. Diabetes Res Clin Pract. 2011;93:228-34.

9. Cédric B, Elaine F. Epidermal stem cells of the skin. Annu Rev Cell Dev Biol. 2006;22:339-73

10. Akhavan M, Junek A, Toma JG, Mill P, Fernandes KLL, Biernaskie J, et al. A dermal niche for multipotent adult skin-derived precursor cells. Nat Cell Biol. 2004:6:1082-93.

11. Lindsay SL, Johnstone SA, Mountford JC, Sheikh S, Allan DB, Clark L, et al. Human mesenchymal stem cells isolated from olfactory biopsies but not bone enhance CNS myelination in vitro. Glia. 2013;61:368-82.

12. Zomer HD, GKdS V, Delben PB, Heck D, TdS J, Trentin AG. In vitro comparative study of human mesenchymal stromal cells from dermis and adipose tissue for application in skin wound healing. J Tissue Eng Regen Med. 2019:13:729-41.

13. Mehdi $N$, Laurence L. Foreskin as a source of immunotherapeutic mesenchymal stromal cells. Immunotherapy. 2017;9:207-17.

14. Bogatcheva NV, Coleman ME. Conditioned medium of mesenchymal stromal cells: a new class of therapeutics. Biochemistry (Moscow). 2019;84: 1375-89.

15. Khanh NM, Eben A. Bioactive factor delivery strategies from engineered polymer hydrogels for therapeutic medicine. Prog Polym Sci. 2014;39:123665.

16. Liu K, Chen C, Zhang H, Chen Y, Zhou S. Adipose stem cell-derived exosomes in combination with hyaluronic acid accelerate wound healing through enhancing re-epithelialization and vascularization. Br J Dermatol. 2019;181:854-6.

17. Gazzabin L, Serantoni S, Palumbo FP, Giordan N. Hyaluronic acid and metallic silver treatment of chronic wounds: healing rate and bacterial load control. J Wound Care. 2019;28:482-90.

18. Won-Serk K, Byung-Soon P, Jong-Hyuk S, Jun-Mo Y, Seok-Beom P, SahngJune $K$, et al. Wound healing effect of adipose-derived stem cells: a critical role of secretory factors on human dermal fibroblasts. J Dermatol Sci. 2007; 48:15-24.

19. Yu X, Xiangsheng W, Ming Z, Miao Q, Melia B, Li L, et al. Expansion of CD26 positive fibroblast population promotes keloid progression. Exp Cell Res. 2017:356:104-13.

20. Cuttle L, Nataatmadja M, Fraser JF, Kempf M, Kimble RM, Hayes MT. Collagen in the scarless fetal skin wound: Detection with Picrosiriuspolarization. Wound Repair Regen. 2005;13:198-204.

21. Heldin CH, Miyazono K, ten Dijke P. TGF-beta signalling from cell membrane to nucleus through SMAD proteins. Nature. 1997;390:465-71.

22. Kunyu Z, Zhaofeng J, Boguang Y, Qian F, Xiao X, Weihao Y, et al. Adaptable hydrogels mediate cofactor-assisted activation of biomarker-responsive drug delivery via positive feedback for enhanced tissue regeneration. Adv Sci. 2018:5:1800875.
23. Xu X, Xia X, Zhang K, Rai A, Li Z, Zhao P, et al. Bioadhesive hydrogels demonstrating $\mathrm{pH}$-independent and ultrafast gelation promote gastric ulcer healing in pigs. Sci Transl Med. 2020;12:eaba8014.

24. Rui L, Sien L, Meiling Z, Yingrui D, Xiaoyu C, Kongchang W, et al. Synthetic presentation of noncanonical Wnt5a motif promotes mechanosensingdependent differentiation of stem cells and regeneration. Sci Adv. 2019;5: eaaw3896.

25. Dongrui M, Hsiang KJE, Keng LW, Teik LS, Choong CAW. In vitro characterization of human hair follicle dermal sheath mesenchymal stromal cells and their potential in enhancing diabetic wound healing. Cytotherapy. 2015;17:1036-51.

26. Stojadinovic O, Pastar I, Vukelic S, Mahoney MG, Brennan D, Krzyzanowska A, et al. Deregulation of keratinocyte differentiation and activation: a hallmark of venous ulcers. J Cell Mol Med. 2008;12:2675-90.

27. Hehenberger K, Kratz G, Hansson A, Brismar K. Fibroblasts derived from human chronic diabetic wounds have a decreased proliferation rate, which is recovered by the addition of heparin. J Dermatol Sci. 1998;16:144-51.

28. Lerman OZ, Galiano RD, Armour M, Levine JP, Gurtner GC. Cellular dysfunction in the diabetic fibroblast : impairment in migration, vascular endothelial growth factor production, and response to hypoxia. J Med Res. 2003;162:303-12.

29. Fui LW, Lok MPW, Govindasamy V, Yong TK, Lek TK, Das AK. Understanding the multifaceted mechanisms of diabetic wound healing and therapeutic application of stem cells conditioned medium in the healing process. J Tissue Eng Regen Med. 2019;13:2218-33.

30. Kunkemoeller B, Kyriakides TR. Redox Signaling in Diabetic Wound Healing Regulates Extracellular Matrix Deposition. Antioxid Redox Signal. 2017;27: 823-38.

31. Bermudez DM, Herdrich $B J, X u J$, Lind R, Beason DP, Mitchell ME, et al. Impaired biomechanical properties of diabetic skin: implications in pathogenesis of diabetic wound complications. J Med Res. 2011;178: 2215-23.

32. Bermudez DM, Herdrich BJ, Xu J, Lind R, Beason DP, Mitchell ME et al. Impaired biomechanical properties of diabetic skin implications in pathogenesis of diabetic wound complications. Am J Pathol. 2011;178: $2215-23$.

33. Wei Z, Abd T, Jayadave S, James V, Sharon H, Kiran D, et al. Effects of a synthetic retinoid on skin structure, matrix metalloproteinases, and procollagen in healthy and high-risk subjects with diabetes. J Diabetes Complicat. 2011;25:398-404.

34. Sasabe R, Sakamoto J, Goto K, Honda Y, Kataoka H, Nakano J, et al. Effects of joint immobilization on changes in myofibroblasts and collagen in the rat knee contracture model. J Orthop Res. 2017;35:1998-2006.

35. Nagaraju CK, Robinson EL, Abdesselem M, Trenson S, Dries E, Gilbert G, et al. Myofibroblast Phenotype andReversibility of Fibrosis in Patients With EndStage Heart Failure. J Am College Cardiol. 2019;73:2267-82.

36. Page-McCaw A, Ewald AJ, Werb Z. Matrix metalloproteinases and the regulation of tissue remodelling. Nat Rev Mol Cell Biol. 2007;8:221-33.

37. Meinhard S, Delphine J, Alain M. TGF-beta-induced SMAD signaling and gene regulation: consequences for extracellular matrix remodeling and wound healing. J Dermatol Sci. 2004;35:83-92.

38. Zhang T, Wang X-F, Wang Z-C, Lou D, Fang Q-Q, Hu Y-Y, et al. Current potential therapeutic strategies targeting the TGF- $\beta /$ Smad signaling pathway to attenuate keloid and hypertrophic scar formation. Biomed Pharmacother. 2020;129:110287.

39. van den Bogaerdt AJ, van der Veen VC, van Zuijlen PPM, Reijnen L, Verkerk M, Bank RA, et al. Collagen crosslinking by adipose-derived mesenchymal stromal cells and scar-derived mesenchymal cells: Are mesenchymal stromal cells involved in scar formation? Wound repair and regeneration : official publication of the Wound Healing Society [and] the European Tissue Repair Society. 2009;17:548-58.

40. Steven M, John D, Jonathan S, Philip M. Fibroblast migration and collagen deposition during dermal wound healing: mathematical modelling and clinical implications. Phil Trans R Soc A. 2006;364:1385-405.

41. Martin P. Wound healing--aiming for perfect skin regeneration. Science (New York, NY). 1997;276:75-81.

42. Sizheng Z, Wenjin W, Shuangbai Z, Guoyou Z, Jizhou H, Qingfeng L. A novel model for cutaneous wound healing and scarring in the rat. Plast Reconstr Surg. 2019;143:468-77.

43. Wetzler C, Kämpfer H, Stallmeyer B, Pfeilschifter J, Frank S. Large and sustained induction of chemokines during impaired wound healing in the 
genetically diabetic mouse: prolonged persistence of neutrophils and macrophages during the late phase of repair. J Invest Dermatol. 2000;115: 245-53.

44. Wu YS, Chen SN. Extracted triterpenes from Antrodia cinnamomea reduce the inflammation to promote the wound healing via the STZ inducing hyperglycemia-diabetes mice model. Front Pharmacol. 2016;7:154.

45. Si-Qian G, Chen C, Xiao-Qian N, Long-Jian L, Yan Z, Jian-Qing G. Topical application of hydroxysafflor yellow $A$ accelerates the wound healing in streptozotocin induced T1DM rats. Eur J Pharmacol. 2018;823:72-8.

46. Singer AJ, Clark RA. Cutaneous wound healing. N Engl J Med. 1999;341:738-46.

\section{Publisher's Note}

Springer Nature remains neutral with regard to jurisdictional claims in published maps and institutional affiliations.

Ready to submit your research? Choose BMC and benefit from:

- fast, convenient online submission

- thorough peer review by experienced researchers in your field

- rapid publication on acceptance

- support for research data, including large and complex data types

- gold Open Access which fosters wider collaboration and increased citations

- maximum visibility for your research: over $100 \mathrm{M}$ website views per year

At BMC, research is always in progress.

Learn more biomedcentral.com/submissions 